\title{
Germination ecology of Ambrosia artemisiifolia L. and Ambrosia trifida L. biotypes suspected of glyphosate resistance
}

\section{Research Article}

Giovanni Dinelli ${ }^{1}$, Ilaria Marotti ${ }^{1}$, Pietro Catizone ${ }^{1}$, Sara Bosi ${ }^{1}$, Asif Tanveer², Rana Nadeem Abbas ${ }^{2}$, Danijela Pavlovic ${ }^{3, *}$

${ }^{1}$ Department of Agricultural Sciences, University of Bologna, 40127 Bologna, Italy

${ }^{2}$ Department of Agronomy, University of Agriculture, 38040 Faisalabad, Pakistan

3/nstitute for Plant Protection and Environment, Department of Herbology, 11000 Belgrade, Serbia

Received 13 May 2012; Accepted 06 November 2012

Abstract: The germination ecology of Ambrosia artemisifolia and $A$. trifida glyphosate susceptible biotypes sampled in marginal areas, was compared with that of the same species but different biotypes suspected of glyphosate resistance, common and giant ragweed, respectively. The suspected resistant biotypes were sampled in Roundup Ready ${ }^{\circledR}$ soybean fields. Within each weed species, the seeds of the biotype sampled in marginal area were significantly bigger and heavier than those of the biotype sampled in the soybean fields. A. artemisiifolia biotypes exhibited a similar dormancy and germination, while differences between $A$. trifida biotypes were observed. A. artemisifolia biotypes showed similar threshold temperature for germination, whereas, the threshold temperature of the susceptible $A$. trifida biotype was half as compared to that of the resistant $A$. trifida biotype. No significant differences in emergence as a function of sowing depth were observed between susceptible $A$. artemisiifolia and suspected resistant $A$. trifida biotype, while at a six-cm seedling depth the emergence of the $A$. artemisiifolia susceptible biotype was 2.5 times higher than that of the $A$. trifida suspected resistant biotype. This study identified important differences in seed germination between herbicide resistant and susceptible biotypes and relates this information to the ecology of species adapted to Roundup Ready ${ }^{\circledR}$ fields. Information obtained in this study supports sustainable management strategies, with continued use of glyphosate as a possibility.

Keywords: Ambrosia artemisiifolia • Ambrosia trifida • Glyphosate resistance • Seed ecology

(c) Versita Sp. z 0.0 .

\section{Introduction}

Common (Ambrosia artemisiifolia L.) and giant ragweed (A. trifida L.), annual and North American native species, are considered serious or troublesome summer weeds in crop systems in both the Eastern and Southeastern United States [1]. Since the mid-20 $0^{\text {th }}$ century, common and giant ragweed have migrated to farm fields and early successional sites in Europe, South America, and Asia [2,3]. Common and giant ragweed are among the most competitive weed species for summer crops. Giant ragweed has caused corn (Zea mays L.) and soybean [Glycine max (L.) Merr.] grain yield losses $\geq 50 \%$ at a weed population density of 1 plant $\mathrm{m}^{-2}$ [4-6] A $30 \%$ reduction in yield in soybean was observed in the presence of a common ragweed density of 1 plant per $1.5 \mathrm{~m}^{2}$ [7]. In addition to their detrimental effects on crop yield, common and giant ragweed produce copious pollen that is a major aeroallergen of the world's temperate regions [8]. The genus Ambrosia has long been recognized as a significant cause of allergic rhinitis, with an estimated $10 \%$ of the US population (32 million) considered ragweed sensitive [9].

Year to-year persistence of common and giant ragweed populations require a period of seed dormancy immediately following autumn seed dispersal. Seeds 
of nonwinter-hardly temperate plants, such as $A$. artemisiifolia and $A$. trifida, may be dormant in the fall and require overwintering to break dormancy. In this case, dormancy prevents germination late in the growing season and insures seed survival until spring [10]. The primary dormancy of $A$. artemisiifolia is mainly due to the presence of inhibitors such as phenolic compounds (similar to chlorogenic acid) and abscissic acid [11], while in $A$. trifida seed dormancy can be attributed to an inhibitory mechanism within the embryo (embryo dormancy) or constraints on the embryo imposed by the embryo-covering structures (coat-imposed dormancy) $[12,13]$. For both species prolonged periods of cold stratification (several weeks at $4-5^{\circ} \mathrm{C}$ ), simulating what occurs under field conditions in the winter season, remove primary seed dormancy promoting germination [14-16]. Particular conditions occurring during stratification (ie alternating temperature regimes in darkness conditions) can induce in $A$. artemisiifolia a secondary dormancy $[17,18]$.

The non-dormant seeds of $A$. artemisiifolia and $A$. trifida germinate in a wide range of temperatures, in particular under light conditions [19,20]. After 11 weeks of seed stratification the highest germination of common ragweed was observed at the constant temperature of $25^{\circ} \mathrm{C}$ under light conditions [20]. A. trifida non-dormant seeds germinate under a wide range of temperatures (from 8 to $41^{\circ} \mathrm{C}$ ) with an optimum between 20 and $24^{\circ} \mathrm{C}$ [19]. Emergence of common ragweed seedlings occurs mainly from soil surface and drastically decreases by increasing planting depth [15]. Abul-Fatih and Bazzaz [19] reported that giant ragweed emerged from seeds buried over a range of depths from 0.5 to $16 \mathrm{~cm}$, but maximum emergence occurred when seeds were buried at 1 to $4 \mathrm{~cm}$.

Common and giant ragweed are included in the list of 22 weed species that have already evolved glyphosate resistant biotypes [21]. The first glyphosate resistant common and giant ragweed populations were confirmed in 2004, in Missouri (USA) and in Ohio (USA), respectively [21]. After the first occurrence, glyphosate resistant common and giant ragweed populations were confirmed in many parts of USA [21].

The main aim of the present paper was to investigate the role of germination ecology as a factor contributing to the escape of suspected resistant biotypes of $A$. trifida and $A$. artemisifolia to the activity of glyphosate. For the purposes of this research on the investigated biotypes we examined: a) glyphosate dose-response, b) seed polymorphism by image analysis, c) seed dormancy, d) germination of non-dormant seeds at different temperatures and e) emergence under laboratory conditions.

\section{Experimental Procedures}

\subsection{Materials}

Common and giant ragweed seeds, sampled in late summer of 2005 in Arkansas (USA), were kindly provided by Syngenta Crop Protection-US (Greensboro, North Caroline, USA). The seeds of suspected glyphosate resistant common ragweed biotype (AAR) were collected in a soybean field from plants that had survived three repeated applications of glyphosate (each dose equal to $0.78 \mathrm{~kg} \mathrm{ae} / \mathrm{ha}$ ) during the soybean growing cycle. The field had been continuous Roundup Ready ${ }^{\circledR}$ soybean and no-tillage for at least six years and glyphosate was the only herbicide used. The seeds of glyphosate susceptible common ragweed biotype (AAS) were sampled at a roadside, approximately two km away from the collection site of AAR biotype, with no documented glyphosate usage in the five years before the sampling. The seeds of suspected glyphosate resistant giant ragweed biotype (ATSR) were collected in a soybean field from plants that had survived two repeated applications of glyphosate (each dose equal to $0.82 \mathrm{~kg}$ ae/ha) during the soybean growing cycle. The field had been continuous Roundup Ready ${ }^{\circledR}$ soybean and notillage for at least 5 years and glyphosate was the main herbicide used, with some occasional applications of paraquat occurred. The seeds of glyphosate susceptible giant ragweed biotype (ATS) were sampled in field margins never treated with glyphosate and located on the same farm where the ATSR biotype was collected.

The collected seeds were stored in the dark at constant temperature $\left(20^{\circ} \mathrm{C}\right)$ and $50 \%$ relative humidity $(\mathrm{RH})$ until further use. All the subsequent analyses were carried out within three months after seed sampling from original sites.

\subsection{Dose-response tests}

For each biotype, seedlings in the cotyledon growth stage were individually transplanted into pots $(3 \mathrm{~cm}$ radius; $350 \mathrm{~mL}$ volume) containing a 1:1 (VN) peat:sand sterile potting mix. Plants were placed in a growth chamber with controlled environment (day: $25^{\circ} \mathrm{C} ; 70 \% \mathrm{RH}$; night: $20^{\circ} \mathrm{C}$; $50 \% \mathrm{RH} ; 12-\mathrm{h}$ photoperiod, with artificial illumination at 550 $\mu \mathrm{mol}$ photons $\mathrm{s} / \mathrm{m}$ ). Plants were sub-irrigated as needed. Dose-response curves of Ambrosia spp biotypes were determined at the 4-6 true leaf stage. Plants were sprayed with glyphosate at the doses of $0,45,360,740$, and $1480 \mathrm{~g}$ ae/ha (Roundup Bioflow, $360 \mathrm{~g}$ ae /L, Monsanto). The sprayer was equipped with a flat-fan nozzle at a height of $50 \mathrm{~cm}$ with an output volume equivalent to $185 \mathrm{~L} / \mathrm{ha}$. The experimental design was a randomized complete block with four biotypes, five herbicide doses and four replications of 25 plants. Plants were assessed 
28 days after treatment (DAT) and were scored as dead or alive. Nonlinear regression analysis and ANOVA were used to determine the effect of glyphosate dose on plant survival of each ragweed biotype. A sigmoidal log-logistic model [22] was used to relate number of survived plants as a percent of the untreated check $(\mathrm{Y})$ to glyphosate dose $(x)$ according to the following formula: $\left.\mathrm{Y}=\mathrm{a} / 1+\mathrm{e}^{-(\mathrm{x}-\mathrm{LD}}{ }_{50}\right) / \mathrm{b}$. In this equation, $\mathrm{a}$ is the difference of the upper and lower response limits (asymptotes), $\mathrm{LD}_{50}$ is the herbicide dose required to kill $50 \%$ of individuals, and $b$ is the slope of the curve around $L D_{50}$. The resistance index (RI) was determined by dividing the $L D_{50}$ value of each $R$ biotype by the $L D_{50}$ of the $S$ biotype.

\subsection{Seed morphology and weight}

For each biotype five replicates of 20 seeds were randomly selected from the seed bulk collected at the original sampling site. For each replicate the seeds were placed on a silicon gel support and scanned at $720 \mathrm{dpi}$ using a flatbed scanner, according to the procedure proposed by Sako et al. [23]. Both sides of the seeds were obtained, such that each seed had complementary side images. For the side image, each seed was oriented so that the conical beak pointed up. The seed images were then processed using the image analysis software Assess (American Phytopathological Society Press). Thirteen different features were extracted from the seed images. Features included colour (red, blue, and green components), structural characteristics, and ratios of various structural characteristics. Red, blue, and green colour components of each seed were extracted by averaging, independently, the red, green, and blue components of the pixels representing the seed (also called seed blob). The intensity of each colour component was measured (values ranging from 0 to 255). Structural characteristics included seed width (minor axis), height (major axis), area, perimeter, length of central (or major) spine and the total number of spines. Ratios of various structural characteristics, the roundness, elongation and compactness factors were determined. The roundness (Ro) was calculated according to the following formula: $\mathrm{Ro}=(4 \mathrm{xp} \times$ area $) /$ perimeter $^{2}$. The elongation was obtained dividing the seed height (major axis) by the seed width (minor axis), while the compactness (Co) was computed according to the following formula: $\mathrm{Co}=((4 \mathrm{x} \text { area/p }) / \text { seed height })^{0.5}$. Elongation, roundness and compactness are indicators of the circularity of the seed. Seeds with shape closer to a perfect circle present values of elongation, roundness and compactness closer to one [24]. The morphological features (colour, structural characteristics and related ratios) are mean values of parameters extracted from both side images of seed.
For each biotype five replicates of 100 seeds were randomly selected from the seed bulk collected in the original sampling site and weighted out. Morphological and weight data were analyzed by ANOVA according to a completely randomized design.

\subsection{Dormancy and germination tests}

Seeds were disinfected with sodium hypochlorite $(0.5 \%$ $\mathrm{v} / \mathrm{v}$ ) for $10 \mathrm{~min}$ before use and air dried. For each biotype the seeds were stratified in sterilized wet sand in the dark at the temperature of $4^{\circ} \mathrm{C}$ for $0,1,2,3$ and 4 weeks. After the stratification, the seeds were imbibed on a double sheet of moistened (7 $\mathrm{ml}$ of distilled water) filter paper (Whatman no.1) and placed in $12 \mathrm{~cm}$ Petri dishes. Seeds were incubated at the constant temperature of $25 \pm 0.5^{\circ} \mathrm{C}$ under light/dark (12/12 h) photoperiod. Climatic cabinets were equipped with white light sources (PHILIPS THL 20W/33) by fluorescent tubes $(20 \mu \mathrm{mol}$ photons $\mathrm{s} / \mathrm{m}$ ). A spectroradiometer (model 1800, Licor Inc., Lincoln, NE, USA) was used for the control of irradiance. Moreover, after the stratification treatment of 4 weeks, seeds from each biotype were incubated at different constant temperatures $\left(10,15,20\right.$ and $\left.25^{\circ} \mathrm{C}\right)$ under light/dark $(12 / 12 \mathrm{~h})$ photoperiod in the climatic cabinets previously described.

A completely randomized design (randomization of Petri plate positions every 2 d) was used with four replicates (50 seeds) for each biotype, stratification time and germination temperature. Germinated seeds (defined as cotyledon appearance) were counted daily. Germination counts were stopped when final germination percentages were reached (approximately after 2 weeks). Data were analyzed with a two-way ANOVA with biotype and stratification time as the main factors. In addition, minimum temperatures for seed germination were calculated using the " $x$ intercept" method previously utilized on other species [22]. Briefly, this method consists of calculating a linear regression using temperature as the independent variable, while the dependent variable was \% germination per day (GD), expressed by the formula: $G D=\%$ germination/ days necessary to complete germination. The point of intersection of this straight line with the axis is considered the germination temperature threshold. A completely randomized design (randomization of pot position every 2 d) was used with four replicates (10 seeds) for each biotype and sowing depth.

\subsection{Emergence tests}

Non-dormant seeds (stratified for 4 weeks at $4^{\circ} \mathrm{C}$ ) of each biotype were planted in sandy loam soil in $10-\mathrm{cm}-$ diameter by $10-\mathrm{cm}$-deep plastic pots at different depths: $0,1,2,4$ and $6 \mathrm{~cm}$ for common ragweed biotypes and 
0, 1, 3, 6 and $9 \mathrm{~cm}$ for giant ragweed biotypes. Pots were subirrigated as needed. Pots were covered with aluminium foil for $24 \mathrm{~h}$ and then exposed to a photoperiod/temperature cycle of $13 \mathrm{~h}$ of light at $27^{\circ} \mathrm{C}$ and $11 \mathrm{~h}$ of dark at $22^{\circ} \mathrm{C}$. Seedlings were considered emerged when the two cotyledons could be discerned visually. Data were analyzed with a two-way ANOVA with biotype and sowing depth as main factors.

\subsection{Statistical analysis}

Percentage data were arcsine square root transformed to improve normality and homogeneity of variance. Experiments were repeated. Data for the two runs of the experiments were pooled because variances were homogenous according to Bartlett's test and a nonsignificant experiment by treatment interaction occurred [25]. All significant $(P<0.05)$ effects were tested for differences using the LSD multiple range tests. ANOVAs and regression analyses were performed using CoStat (ver. 6.002, CoHort Software).

\section{Results}

\subsection{Dose-response assays}

The response of each Ambrosia biotype to increasing glyphosate dose was fitted to a sigmoidal log-logistic model, with regression coefficients ranging between 0.95 and 0.99. The $L D_{50}$ value for the AAR was significantly higher than that for the AAS, indicating that the AAR biotype was physiologically resistant to glyphosate (Figure 1). No individual of the AAS biotype survived at doses $>720 \mathrm{~g}$ ae/ha, while at the dose of $720 \mathrm{~g}$ ae/ha approximately $25 \%$ of AAR individuals survived. The $\mathrm{RI}$ (resistance index $=\mathrm{LD}_{50}$ of resistant biotype/LD $\mathrm{LD}_{50}$ of susceptible biotype) of the AAR biotype was 4.2 .

During the dose-response test different morphological responses of AAR and AAS plants were observed. In particular, at the higher herbicide doses (720 and $1440 \mathrm{~g}$ ae/ha) within 3-10 DAT in both AAR and AAS plants the progressive and irreversible dehydration of treated leaves was observed. From 10-21 DAT the AAS plants died, while surviving AAR plants recovered by producing new leaves from the growing points

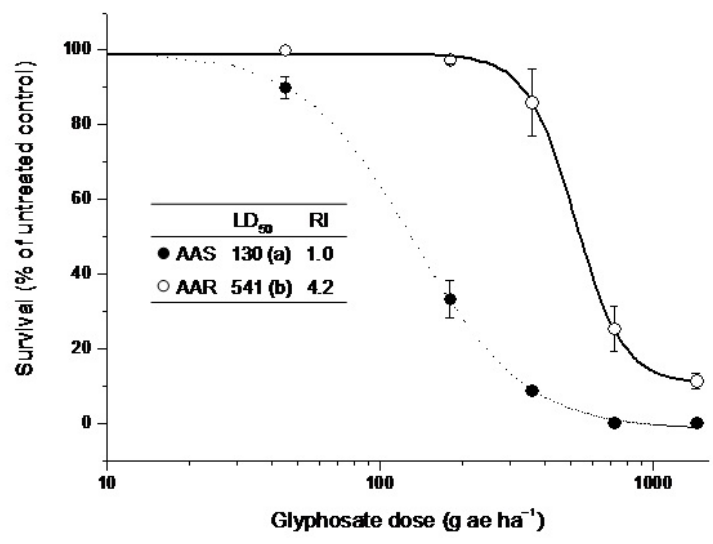

Figure 1. Dose-response assay of Ambrosia artemisiifolia biotypes (dotted line = AAS, straight line = AAR) treated at 4-6 true leaf stage with different glyphosate doses. Lines describe the predicted survival responses according to the equation reported in the Materials and methods section. Data are mean $\pm \mathrm{SE}$. In the inset, for each biotype the $L_{50}$ value ( $\mathrm{g}$ ae/ha), resistance index (RI) and statistical significance (within brackets different letters represent values significantly different at $\mathrm{P}=0.05$ based on Fisher's LSD) are reported.

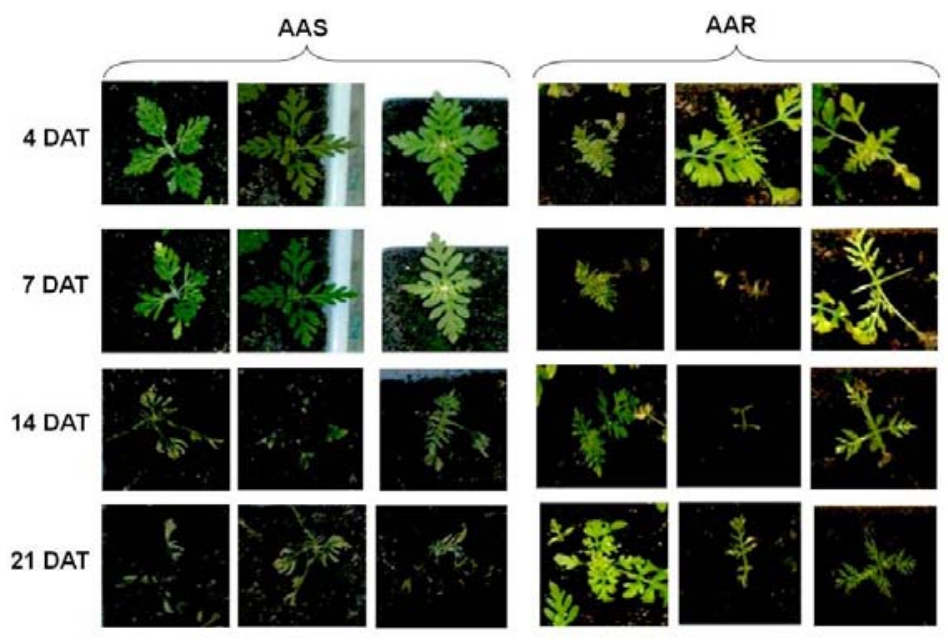

Figure 2. Different morphological responses of glyphosate-susceptible AAS and resistant AAR biotypes between 4 and 21 days after the treatment with $720 \mathrm{~g}$ ae/ha. The white arrows indicates the growth of new leaves form meristematic tissues. 
(Figure 2). In contrast, the $\mathrm{LD}_{50}$ value of ATSR was not significantly different from ATS (Figure 3 ).

\subsection{Seed morphology}

The visual assessment of Ambrosia seeds allowed to clearly discriminate between susceptible and suspected resistant biotypes within each species (Figure 4). The seeds of AAS and ATS biotypes were bigger than those of AAR and ATSR, respectively. Within each species no substantial coat colour differences were noted. The seed image analysis confirmed the visual inspection. In regards to dimensional parameters, the major and minor axes, perimeter and area of AAS and ATS seeds were significantly higher than those of AAR and ATSR seeds, respectively (Table 1). The shape of AAR and ATSR seeds was more elongated than that of AAS and ATS seeds, respectively, while no differences were detected for seed roundness and compactness (Table 1). Within each species, the same number of seed spines was found in susceptible and suspected resistant biotypes. The length of the seed central spine was significantly higher in the AAR than in AAS biotype. In addition, also the ratio between the central spine length and the major axis length was significantly higher in the AAR than in the AAS biotype. In contrast, the seed central spine of ATS biotype was significantly longer than that of ATSR biotype, while no difference was observed for the central-spine-to-major-axis ratio. Within each species similar color components were observed in the investigated biotypes (Table 1).

Finally, the differences in dimensional features reflected differences in seed weight: larger dimensional parameters generally corresponded to heavier seeds. In particular, the weight of AAS seeds was approximately 1.5 times the weight of AAR seeds, while the weight of ATS biotype was approximately 1.2 times the weight of ATSR seeds. These weight differences were statistically significant (Table 1).

\subsection{Dormancy}

AAS and AAR biotypes did not differ significantly from each other in dormancy after seed exposure to low temperature $\left(4^{\circ} \mathrm{C}\right)$ at different time intervals (Figure $5 \mathrm{a}$ ).

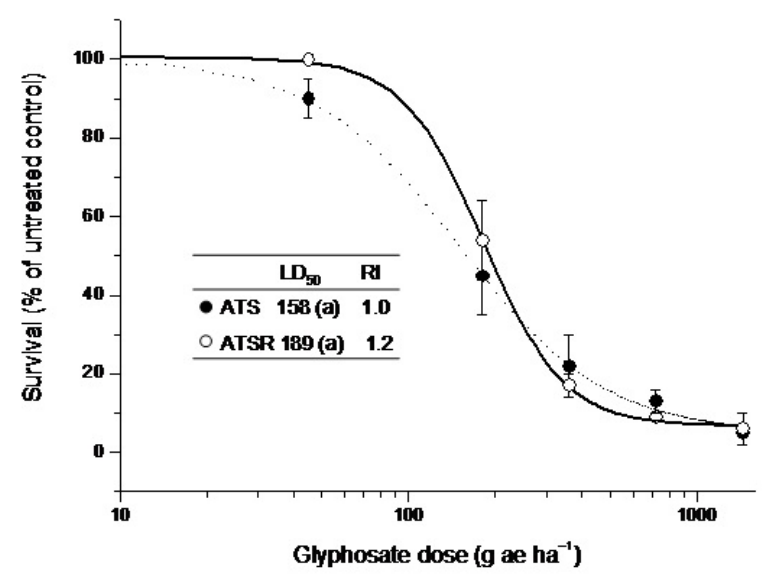

Figure 3. Dose-response assay of Ambrosia trifida biotypes (dotted line $=$ ATS, straight line $=$ ATSR) treated at 4-6 true leaf stage with different glyphosate doses. Lines describe the predicted survival responses according to the equation reported in the Materials and methods section. Data are mean $\pm S E$. In the inset, for each biotype the $L_{50}$ value ( $\mathrm{g}$ ae/ha), resistance index (RI) and statistical significance (within brackets different letters represent values significantly different at $P=0.05$ based on Fisher's LSD) are reported.

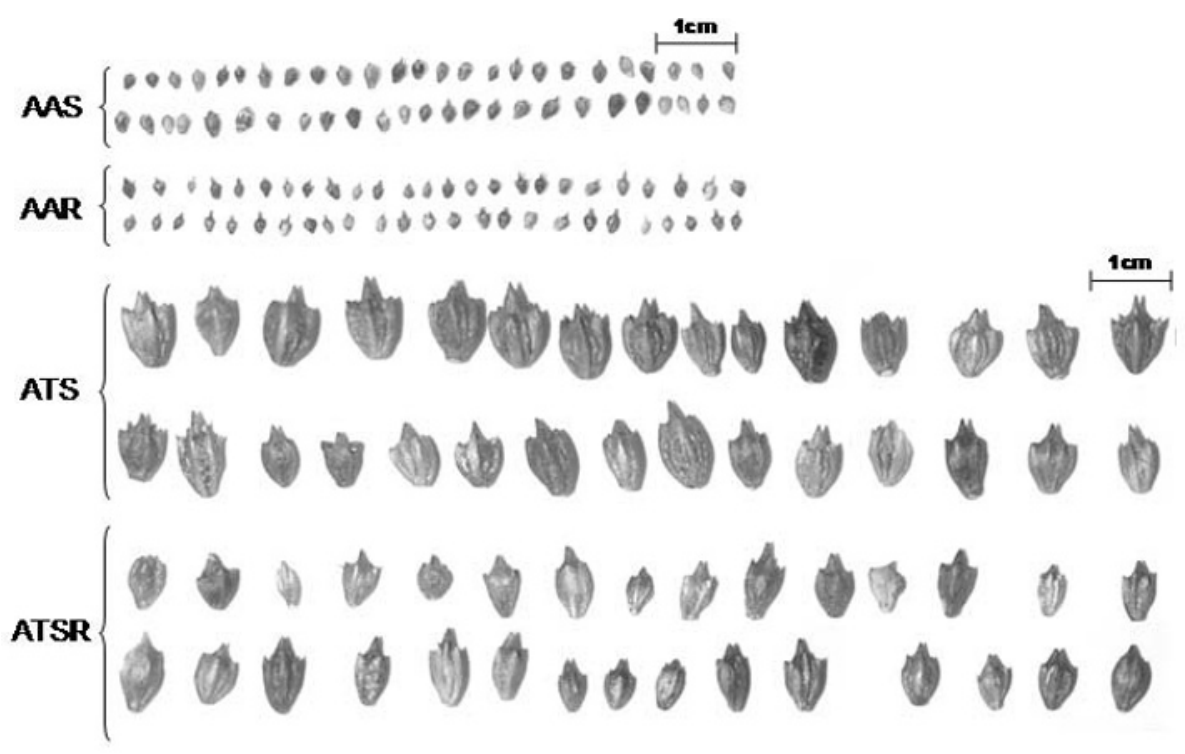

Figure 4. Seed images of Ambrosia artemisiifolia (AAS, AAR) and Ambrosia trifida (ATS, ATSR) biotypes. 


\begin{tabular}{|c|c|c|c|c|}
\hline Species & \multicolumn{2}{|c|}{ A. artemisiifolia } & \multicolumn{2}{|c|}{ A. trifida } \\
\hline Biotype & AAS & AAR & ATS & ATSR \\
\hline Weight (100 seeds, g) & $0.43 \pm 0.01(a)$ & $0.28 \pm 0.02(b)$ & $5.36 \pm 0.44\left(a^{\prime}\right)$ & $4.39 \pm 0.24\left(b^{\prime}\right)$ \\
\hline Major axis (mm) & $3.32 \pm 0.30(a)$ & $3.01 \pm 0.28(b)$ & $9.70 \pm 1.05\left(a^{\prime}\right)$ & $7.94 \pm 1.47\left(b^{\prime}\right)$ \\
\hline Minor axis (mm) & $2.26 \pm 0.21(\mathrm{a})$ & $1.86 \pm 0.22(b)$ & $6.36 \pm 0.73\left(a^{\prime}\right)$ & $4.70 \pm 0.78\left(b^{\prime}\right)$ \\
\hline Perimeter (mm) & $9.62 \pm 0.80(a)$ & $8.62 \pm 0.90(b)$ & $29.03 \pm 3.42\left(a^{\prime}\right)$ & $22.37 \pm 4.12\left(b^{\prime}\right)$ \\
\hline Area $\left(\mathrm{mm}^{2}\right)$ & $5.50 \pm 0.74(a)$ & $3.78 \pm 0.71(b)$ & $42.34 \pm 7.87\left(a^{\prime}\right)$ & $26.35 \pm 8.12\left(b^{\prime}\right)$ \\
\hline Elongation & $1.48 \pm 0.17(b)$ & $1.64 \pm 0.19(a)$ & $1.53 \pm 0.17\left(b^{\prime}\right)$ & $1.70 \pm 0.22\left(a^{\prime}\right)$ \\
\hline Roundness & $0.75 \pm 0.06(a)$ & $0.68 \pm 0.06(a)$ & $0.63 \pm 0.06\left(a^{\prime}\right)$ & $0.65 \pm 0.06\left(a^{\prime}\right)$ \\
\hline Compactness & $0.80 \pm 0.05(a)$ & $0.75 \pm 0.05(a)$ & $0.76 \pm 0.04\left(a^{\prime}\right)$ & $0.72 \pm 0.05\left(a^{\prime}\right)$ \\
\hline Number of spines & $4.90 \pm 0.55(a)$ & $4.85 \pm 0.49(\mathrm{a})$ & $5.40 \pm 0.50\left(a^{\prime}\right)$ & $5.65 \pm 0.67\left(a^{\prime}\right)$ \\
\hline Central spine (mm) & $0.46 \pm 0.29(b)$ & $0.72 \pm 0.26(a)$ & $2.36 \pm 0.56\left(a^{\prime}\right)$ & $1.77 \pm 0.56\left(b^{\prime}\right)$ \\
\hline $\begin{array}{l}\text { Ratio (central spine/major } \\
\text { axis) }\end{array}$ & $0.14 \pm 0.09(b)$ & $0.25 \pm 0.09(\mathrm{a})$ & $0.25 \pm 0.06\left(a^{\prime}\right)$ & $0.25 \pm 0.05\left(a^{\prime}\right)$ \\
\hline Average red & $153 \pm 18(a)$ & $153 \pm 18(a)$ & $140 \pm 23\left(a^{\prime}\right)$ & $145 \pm 22\left(a^{\prime}\right)$ \\
\hline Average green & $121 \pm 11(\mathrm{a})$ & $121 \pm 12(\mathrm{a})$ & $115 \pm 21\left(a^{\prime}\right)$ & $118 \pm 20\left(a^{\prime}\right)$ \\
\hline Average blue & $140 \pm 23(a)$ & $145 \pm 22(a)$ & $104 \pm 18\left(a^{\prime}\right)$ & $109 \pm 19\left(a^{\prime}\right)$ \\
\hline
\end{tabular}

Table 1. Mean values ( \pm SD) of weight and morphological features of side view images of Ambrosia artemisiifolia and Ambrosia trifida seeds. For each species, different letters within brackets represent values significantly different at $\mathrm{P}<0.05$ based on Fisher's LSD.

The dormancy decrease of each common ragweed biotype as a function of increasing exposure time to low temperature was fit to a linear model (data not shown), with regression coefficients ranging between 0.96 and 0.99 . For both biotypes the lowest dormancy was observed after 28 days (Figure $5 a$ ). In contrast, giant ragweed biotypes exhibited significantly different dormancy levels after the seed exposure to low temperature for 7, 14 and 21 days (Figure $5 b$ ). In general, the low temperature was less effective in breaking the dormancy of ATSR than that of ATS biotype. However, after the exposure for 28 days at $4^{\circ} \mathrm{C}$ no significant difference was observed in the dormancy of both giant ragweed biotypes. The dormancy decrease of each giant ragweed biotype as a function of increasing exposure time to low temperature was fit to a polynomial model (data not shown), with regression coefficients ranging between 0.98 and 0.99 .

\subsection{Germination}

The optimum temperature required for germination after seed stratification at low temperature for four weeks was $25^{\circ} \mathrm{C}$ for all tested biotypes (Figure $6 \mathrm{a}, \mathrm{b}$ ). In addition, for the whole range of tested temperatures, no germination differences between AAS and AAR biotypes were observed (Figure 6a). No differences in germination between ATS and ATSR biotypes were found at 20 and $25^{\circ} \mathrm{C}$, while at 10 and $15^{\circ} \mathrm{C}$ the germination of ATSR biotype was 2.5-4 times lower than ATS biotype
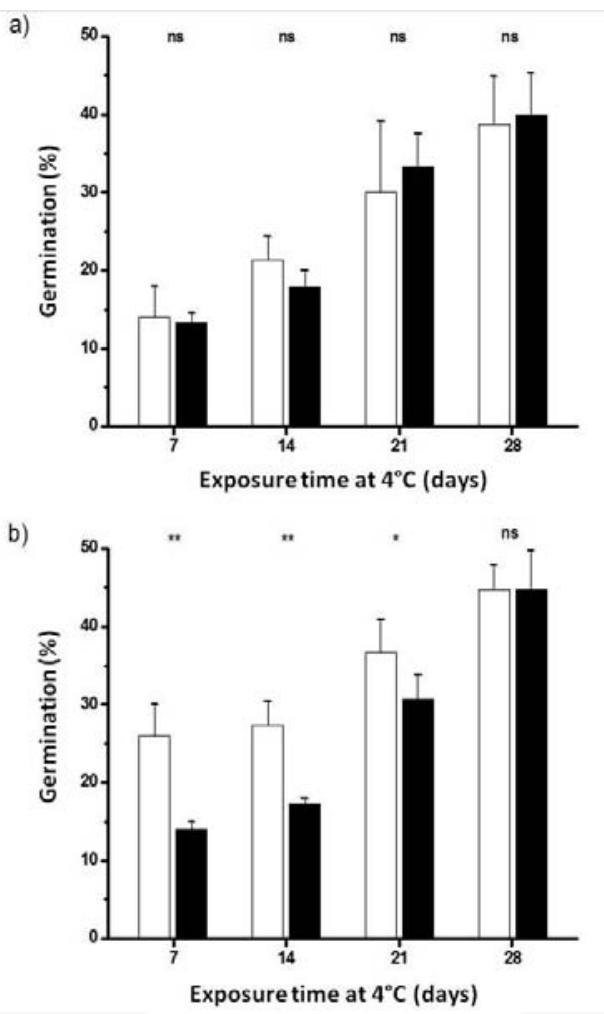

Figure 5. Mean germination $( \pm \mathrm{SE})$ at $25^{\circ} \mathrm{C}(12 \mathrm{~h}$ photoperiod) of Ambrosia artemisiifolia $(A)$ (white bar $=$ AAS, black bar $=$ $\mathrm{AAR}$ ) and Ambrosia trifida (B) biotypes (white bar = ATS, black bar $=$ ATSR) after seed stratification for 1, 2, 3 and 4 weeks at $4^{\circ} \mathrm{C}$. For each time of seed exposure to low temperature the statistical significance is reported (ns = not significant, ${ }^{*} P<0.05$, $\left.{ }^{*} P<0.01\right)$. 
(Figure 6b). Germination data at different temperatures were employed to calculate the minimum (or threshold) temperature for germination of Ambrosia biotypes: AAS and AAR biotypes showed similar values (5.7 and $4.4^{\circ} \mathrm{C}$, respectively), whereas the threshold temperature for ATS biotype $\left(5.4^{\circ} \mathrm{C}\right)$ was approximately half as compared to that of ATSR biotype $\left(9.4^{\circ} \mathrm{C}\right)$ (Figure 7 ).

\subsection{Emergence}

No significant differences in emergence as a function of seed depth were observed among the biotypes of common ragweed: a great proportion of emergence was observed at 1-cm seed depth, while for deeper sowing a strong reduction of emergence was found. At seed depth greater than 4-cm, no germination occurred (Figure 8a). At 1- and 3-cm depth similar emergences were observed for both biotypes of giant ragweed, while at $6-\mathrm{cm}$ depth the emergence of the ATS biotype (16.7\%) was 2.5 times higher than that of the ATSR biotype (6.7\%) (Figure 8b). At seed depth greater than 6-cm no emergence was observed for both biotypes of giant ragweed (Figure $8 b$ ).

a)

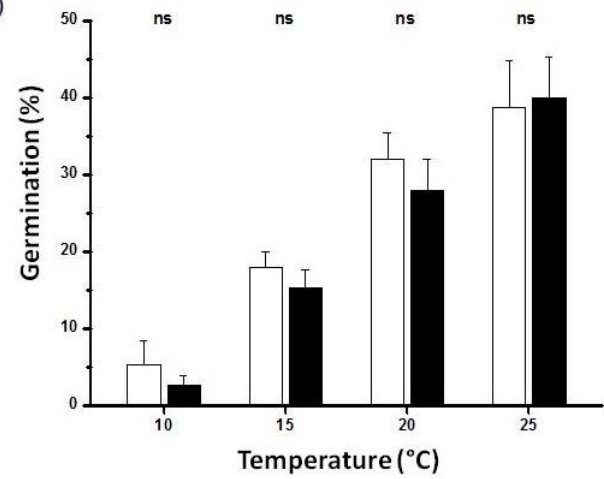

b)

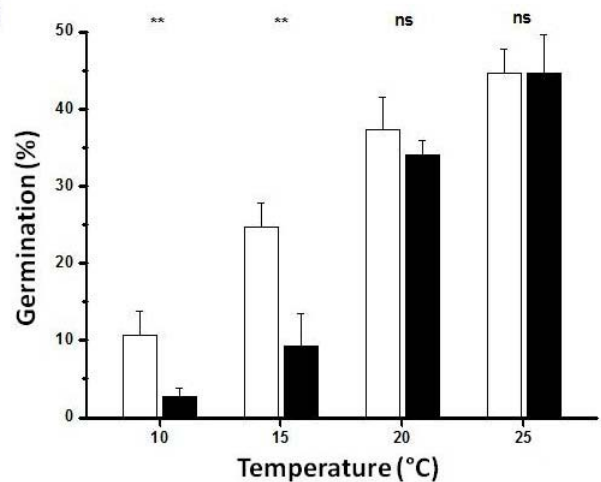

Figure 6. Mean germination $( \pm \mathrm{SE})$ at different temperature $(10,15$, 20 and $25^{\circ} \mathrm{C}, 12 \mathrm{~h}$ photoperiod) of Ambrosia artemisiifolia (A) (white bar = AAS, black bar = AAR) and Ambrosia trifida $(\mathrm{B}$ ) biotypes (white bar $=$ ATS, black bar $=$ ATSR) after seed stratification for 4 weeks at $4^{\circ} \mathrm{C}$. For each germination temperature the statistical significance is reported $\left(\mathrm{ns}=\right.$ not significant, ${ }^{\star} \mathrm{P}<0.05,{ }^{\star \star} \mathrm{P}<0.01$ ).

\section{Discussion}

The dose-response assay confirmed the resistance of the AAR biotype. The observed resistance level $(R I=4.2)$ was consistent with that observed for other weed species which have evolved resistance towards glyphosate such as Conyza canadensis [24], C. bonariensis [27,28], Lolium multiflorum [29], Lolium rigidum [30], Eleusine indica [31]. After glyphosate treatment the morphological response of the AAR biotype was similar to that already reported for several resistant $C$. canadensis biotypes from the USA [24], suggesting the accumulation of the active ingredient on the treated leaves and a limited translocation towards the meristematic tissues of the growing points. However further investigations are in progress in order to elucidate the resistance mechanism (limited herbicide translocation and/or mutation of the EPSP) of the glyphosate resistant common ragweed biotype.

Although repeated glyphosate treatments failed in controlling ATSR biotype under field conditions, the physiological resistance of this biotype was not confirmed by the dose-response assay. Tolerance/

a)
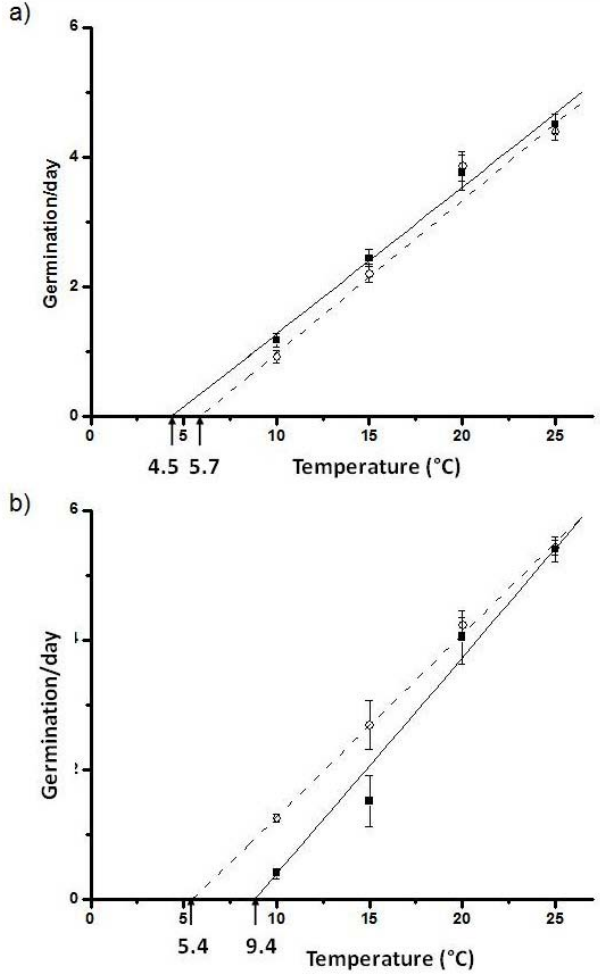

Figure 7. Mean germination per day $( \pm \mathrm{SE}$ ) at different temperature $\left(10,15,20\right.$ and $25^{\circ} \mathrm{C}, 12 \mathrm{~h}$ photoperiod) of Ambrosia artemisiifolia $($ A $)($ dotted line $=$ AAS, straight line $=$ AAR) and Ambrosia trifida (B) biotypes (dotted line = ATS, straight line $=$ ATSR) after seed stratification for 4 weeks at $4^{\circ} \mathrm{C}$. The black arrows indicate for each regression line the intercept (threshold temperature for germination) on $x$-axis. 
resistance to glyphosate is not the unique reason to explain failures in controlling certain weed biotypes. Application rate, weed age and size, spray volume, adjuvants, water quality and interactions with other herbicides affect glyphosate efficacy [32]. Other explanations for weed escapes are that some weed species continue to germinate for a long time during the growing season, including after the last glyphosate application [11,33,34]. This means that certain weed biotypes escape the glyphosate treatment simply by avoiding the herbicide application; so timing of the glyphosate applications is the key to its efficacy [35]. The observed glyphosate failures in controlling ATSR biotype under field conditions were due to ecological escape phenomena or to other factors (environmental conditions, incorrect spraying application) which have limited the phyto-toxic effect of the herbicide.

No substantial differences were observed in the germination ecology of AAS and AAR. The germination of investigated common ragweed biotypes as a function of temperature and duration of stratification was in general agreement with the findings of Pickett and Baskin [20] and Willemsen and Rice [11]. In contrast, ATSR was different as compared to the ATS biotype. In particular, the seeds of ATSR were more dormant and exhibited macro-thermal characteristics with respect to the ATS biotype, as evidenced by the significant different germination after various lengths of stratification and different temperature thresholds for germination. Abul-Fatih and Bazzaz [19] reported that $A$. trifida produces relatively large seeds which germinate at cool temperatures, in a wide range of soil moisture and soil depth, and its seedlings successfully penetrate through soil layers. These features explain the observed early emergence of giant ragweed in early March followed by later emergence of the other prominent annuals [19]. On the other hand, the ATS biotype exhibited germination ecology comparable with that already reported in literature for giant ragweed [19], while the investigated ATSR biotype may avoid glyphosate control for its ecological features due to the delayed emergence. On the whole, obtained results are in agreement with Di Tommaso [37] who demonstrated that ragweed from agricultural areas evolved biotypes characterized by different seed ecology with respect to biotypes from urban areas that were less frequently disturbed.

The seeds of Ambrosia biotypes sampled in agricultural fields (i.e. AAR and ATSR) exhibited significantly different morphological features with respect to those samples at field margins or roadsides (i.e. AAS and ATS). The main observed differences concerned the dimension, weight and shape of seeds:
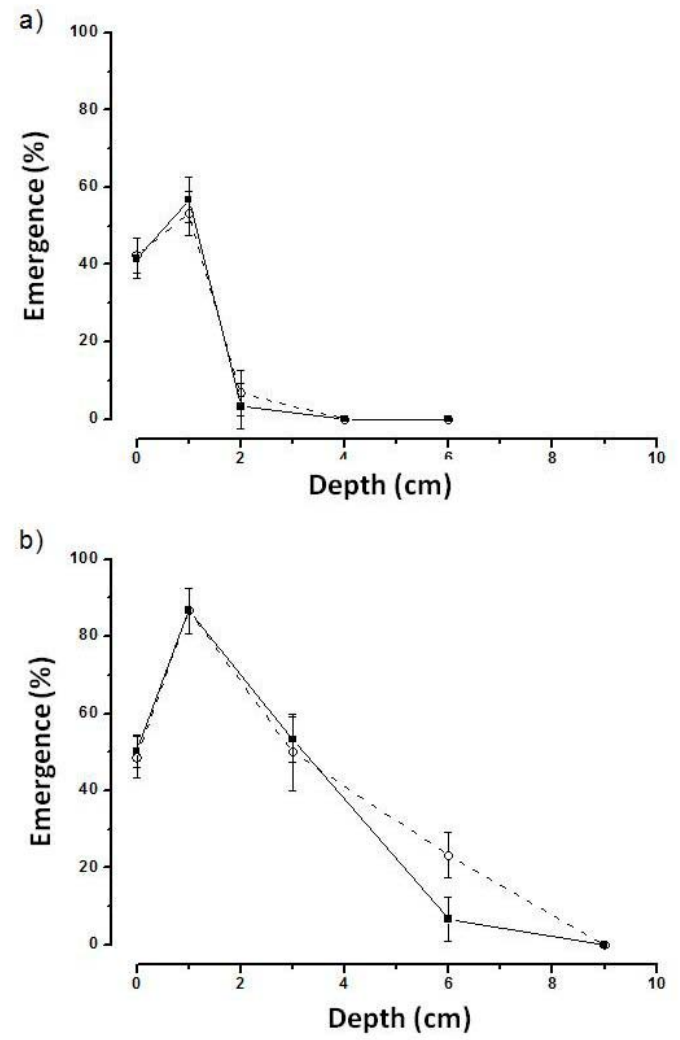

Figure 8. Mean emergence ( \pm SE) of Ambrosia artemisiifolia (A) (dotted line $=$ AAS, straight line $=$ AAR) and Ambrosia trifida $(\mathrm{B})$ biotypes (dotted line $=$ ATS, straight line $=$ ATSR) sown at different depths.

the AAR and ATSR seeds were smaller, lighter and more elongated than AAS and ATS seeds. Considering that AAR and ATSR biotypes were sampled in RR soybean fields with sod seeding management (i.e. no relevant seed burial), it is plausible that the observed morphological seed features have been selected for their best adaptation to this specific agro-ecosystem. The seed morphological features (weight, dimension, shape) deeply influenced at least two different aspects of the weed survival such as emergence and predation. In regards to emergence, the optimal sowing depth was 1-cm. A similar result was observed for other weeds [38]. An explanation of this phenomenon is probably the better hydration conditions for shallow buried seeds (1-cm depth) compared with unburied seeds. For both common and giant ragweed biotypes, emergence strongly declined with increasing seeding depth. AAS and AAR biotypes showed a similar percentage of emergence at different sowing depths. Despite the observed differences in seed dimension and weight, the overall limiting seed weight of both AAR and AAS seeds insured only the emergence from the first soil centimeters, as previously shown by Abul-Fatih and 
Bazzaz [19] and Bassett and Crompton [2]. In contrast, the different morphological features resulted in a better adaptation of the ATS biotype to seed burial than ATSR biotype. This was most likely due to the larger seed reserves available in the larger seeds of the ATS biotype.

Seed predation can occur both on the plant (predispersal) and after the seeds have dispersed and fallen from the mother plant (post-dispersal) [39]. Birds, rodents, and insects are important postdispersal weed seed predators in natural as well as in agricultural habitats [40-42]. For example, rodents were significant seed feeders in no-tillage, but not in conventional tillage systems [43]. Seed predators have a remarkable ability to locate seeds on the soil surface. However, once seeds move into the soil profile the threat of predation is greatly reduced as tillage buries the majority of seeds at depths where predation is minimal. In general, seed ecologists outlined that large-seeded species suffer higher rates of seed predation than small-seeded species $[44,45]$. However, the relationship between seed size and postdispersal predation is still controversial. Moles et al. [46] gathering data from the published literature and field trials on survivorship through post-dispersal seed predation, found a weak positive correlation between seed mass and the percentage of seeds remaining after 24 hours of exposure to post-dispersal seed predators in some Australian sites, and no significant relationship across 280 species from the global literature. A study on temporal patterns of post-dispersal giant ragweed seed predation on the soil surface of a no-tillage corn field as affected by involucre size indicated that rodents and invertebrates were the principal predators of giant ragweed seed [47]. Rodents were the greatest predators of giant ragweed involucres during fall and winter with a preference for large seeds $(>4.8-\mathrm{mm}$ diameter), while during the rest of the year invertebrate predation, with a preference for small involucres (<4.8-mm diameter), dominates [47]. Even if not directly demonstrated by the present investigation, it is plausible that the different morphological features, observed for common and giant ragweed seeds, collected in no-tillage fields (AAR and ATSR) and in non-agricultural sites (AAS and ATS), were also

\section{References}

[1] Bridges D.C., Crop losses due to weeds in the United States. Weed Science Society of America, Champaign, IL, USA, 1992

[2] Bassett I.J., Crompton C.W., The biology of Canadian weeds, 11: Ambrosia artemisiifolia L. selected by specific pre- and post-dispersal predation patterns occurring in different environments.

Comparing the total agricultural and nonagricultural land surface each year treated with herbicides with the worldwide number of weed species and biotypes which until now have evolved physiological resistance towards herbicides, it is evident that the selection of herbicide-resistant traits can be considered a relatively rare event. However, in the last decades the phenomenon of herbicide resistance has drastically increased, currently posing several relevant operational problems in different agro-ecosystems. In particular, these problems are clearly evident where the technology of genetically modified crops resistant to the broad-spectrum herbicide glyphosate was adopted. For example, it was estimated that 200,000 ha in Tennessee and 4,00040,000 ha in Delaware were affected by glyphosateresistant $C$. candensis biotypes, and that soon millions of hectares will be affected in the USA [48-50]. Similar considerations can be extended to other weed species, such as Amaranthus palmeri, A. artemisiifolia and A. trifida, which have evolved glyphosate resistant biotypes. The extensive cultivation of glyphosate tolerant transgenic crops caused one main ecological effect that was not anticipated and predicted: the widespread emergence of glyphosate-resistant weed biotypes [51]. It is reductive to exclusively consider the over reliance and use of glyphosate as the sole cause of this phenomenon. The increased use of glyphosate is probably the main driving force in determining the selection of resistance traits, but also other factors (i.e. no tillage, monoculture, no integrated management) concur in maintaining a high selection pressure in weed populations. On the other hand, the whole set of agronomic practices applied in a certain agro-ecosystem determines the ecological adaptation of weeds, which is more important in assuring weed survival than the physiological resistance towards herbicides. As stated by Sandermann [51], the available literature evidences a certain degree of resistance mismanagement due to inadequate testing of the ecological effects of extensive glyphosate use. The present paper was an attempt to improve the knowledge on this topic, with particular emphasis on seed ecology.

and A. psilostachya, Can. J. Plant. Sci., 1975, 55, 463-476

[3] Bassett I.J., Crompton C.W., The biology of Canadian weeds, 55: Ambrosia trifida L, Can. J. Plant. Sci., 1982, 62, 1002-1010 
[4] Harrison S.K., Regnier E.E., Schmoll J.T., Webb $\mathrm{J}$., Competition and fecundity of Ambrosia trifida in Zea mays, Weed Sci., 2001, 49, 224-229

[5] Baysinger J.A., Sims B.D., Giant ragweed (Ambrosia trifida L.) interference in soybeans (Glycine max), Weed Sci., 1991, 39, 358-362

[6] Webster T.M., Loux M.M., Regnier E.E., Harrison S.K., Giant ragweed (Ambrosia trifida) canopy architecture and interference studies in soybean (Glycine max), Weed Technol., 1994, 8, 559-564

[7] Davis A., Renner K., Sprague C., Dyer L., Mutch D., Integrated Weed Management 2005, Michigan State University, 2005, http://www.msuweeds.com/ michigans_worst_weeds/common_ragweed/

[8] Rybncek O., Jager S., Ambrosia (ragweed) in Europe, Allergy Clin. Immunol. Int., 2001, 13, 6066

[9] Gergen P.J., Turkeltaub P.C., Kovar M.D., The prevalence of allergic skin test reactivity to eight common aeroallergens in the US population: results from the second National Health and Nutrition Examination survey, J. Allergy Clin. Immunol., 1987, 80, 669-679

[10] Wiese A.M., Binning L.K., Calculating the threshold of temperature of development for weeds, Weed Sci., 1987, 35, 177-179

[11] Willemsen R.W., Rice E.L., Mechanism of seed dormancy in Ambrosia artemisiifolia, Am. J. Bot., 1972, 59, 248-257

[12] Schutte B.J., Regnier E.E., Harrison S.K., Primary seed dormancy in Ambrosia trifida (giant ragweed), North Central Weed Sci. Soc., 2004, 59, 119

[13] Davis W.E., Primary dormancy, after-ripening, and the development of secondary dormancy in embrios of Ambrosia trifida, Am. J. Bot., 1930, 17, 58-61

[14] Ballard T.O., Foley M.E., Bauman T.T., Germination, viability, and protein changes during cold stratification of giant ragweed (Ambrosia trifida L.) seed, J. Plant. Physiol., 1996, 149, 229-232

[15] Willemsen R.W., Effect of stratification temperature and germination temperature on germination and the induction of secondary dormancy in common ragweed seeds, Am. J. Bot., 1975a, 62, 1-5

[16] Willemsen R.W., Dormancy and germination of common ragweed seed in the field, Am. J. Bot., 1975b, 62, 639-643

[17] Baskin J.M., Baskin C.C., Ecophysiology of secondary dormancy in seeds of Ambrosia artemisiifolia, Ecology, 1980, 61, 475-480

[18] Bazzaz F.A., Secondary dormancy in the seeds of the common ragweed Ambrosia artemisiifolia, Bull. Torrey. Bot. Club, 1970, 97, 302-305
[19] Abul-Fatih H.A., Bazzaz F.A., The biology of Ambrosia trifida L. II. Germination, emergence and survival, New Phytol., 1979, 83, 817-827

[20] Pickett S.T., Baskin J.M., The role of temperature and light in the germination behavior of Ambrosia artemisiifolia, Bull. Torrey. Bot. Club, 1973, 100, 165-170

[21] Heap I., International survey of herbicide resistant plants, 2012, http://www.weedscience.org

[22] Seber G.A.F., Wild C.J., Nonlinear Regression, Wiley, New York, USA, 1989

[23] Sako Y., Regnier E.E., Daoust T., Fujimura K., Harrison S.K., Miller B., et al., Computer image analysis and classification of giant ragweed seeds, Weed Sci., 2001, 49, 738-745

[24] Dinelli G., Marotti I., Bonetti A., Minelli M., Catizone P., Barnes J., Physiological and molecular insight on the mechanisms of resistance to glyphosate in Conyza canadensis (L.) Cronq. Biotypes, Pestic. Biochem. Physiol., 2006, 86, 30-41

[25] Steel R.G.D., Torrie J.H., Principles and Procedure of Statistics: a Biometric Approach. 2nd edn, McGraw-Hill, New York, USA, 1980

[26] Baxes G., Digital Image Processing, Wiley, New York, USA, 1994

[27] Dinelli G., Marotti I., Bonetti A., Catizone P., Urbano J.M., Barnes J., Physiological and molecular bases of glyphosate resistance in Conyza bonariensis biotypes from Spain, Weed Res., 2008, 48, 1-9

[28] Urbano J.M., Borrego A., Torres V., Leon J.M., Jimenez C., Dinelli G., Barnes J., Glyphosateresistant hairy fleabane (Conyza bonariensis) in Spain, Weed Technol., 2007, 21, 396-401

[29] Perez-Jones A., Park K.W., Polge N., Colquhoun J., Mallory-Smith C.A., Investigating the mechanisms of glyphosate resistance in Lolium multiflorum, Planta, 2007, 226, 395-404

[30] Powles S.B., Lorraine-Colwill D.F., Dellow J.J., Preston C., Evolved resistance to glyphosate in rigid ryegrass (Lolium rigidum) in Australia, Weed Sci., 1998, 46, 604-607

[31] Lee L.J., Ngim J., A first report of glyphosateresistant goosegrass (Elusine indica (L) Gaertn) in Malaysia, Pest. Manag. Sci., 2000, 56, 336-339

[32] Jordan D.L., York A.C., Griffin J.L., Clay P.A., Vidrine P.R., Reynolds D.B., Influence of application variables on efficacy of glyphosate, Weed Technol., 1997, 11, 354-362

[33] Arnold J.C.D., Shaw R., Scharer S.M., Influence of application timing on efficacy of glyphosate in Roundup Ready soybean, Proc. South. Weed Sci. Soc., 1997, 50, 176-177 
[34] Hennen S., Scursoni J., Forcella F., Delayed weed emergence and escape from control in glyphosatetolerant soybean, North Central Weed Sci. Soc., 2002, 57, 126

[35] Payne S.A., Oliver L.R., Weed control programs in drilled glyphosate-resistant soybean, Weed Technol., 2000, 14, 413-422

[36] Scursoni J.A., Forcella F., Gunsolus J., Weed escapes and delayed weed emergence in glyphosate-resistant soybean, Crop. Prot., 2007, 26, 212-218

[37] Di Tommaso A., Germination behaviour of common ragweed (Ambrosia artemisiifolia) populations across a range of salinities, Weed Sci., 2004, 52, 1002-1009

[38] Mohler C.L., Galford A.E., Weed seedling emergence and survival: separating the effects of seed position and soil modification by tillage, Weed Res., 1997, 37, 147-155

[39] White S.S., Renner K.A., Menalled F.D., Landis D.A., Feeding preferences of weed seed predators and effect on weed emergence, Weed Sci., 2007, $55,606-612$

[40] Heggenstaller A.H., Menalled F.D., Liebman M., Westerman P.R., Seasonal patterns in postdispersal seed predation of Abutilon theophrasti and Setaria faberi in three-cropping systems, J. Appl. Ecol., 2006, 43, 999-1010

[41] Louda S.M., Predation in the Dynamics of Seed Generation. In: Leck M.A., Parker V.T., Simpson R.L. (eds) Ecology of Soil Seed Banks, Academic Press, New York, USA, 1989

[42] Menalled F., Smith R., Dauer J., Fox T., Impact of agricultural management on carabid communities and weed seed predation, Agric. Ecosyst. Environ., 2007, 118, 49-54
[43] Brust G.E, House G.I., Weed seed destruction by arthropods and rodents in low-input soybean agroecosystems, Am. Journal Alternative Agr, 1988, 3, 19-25

[44] Hulme P.E., Post-dispersal seed predation and seed bank persistence, Seed Sci. Res., 1998, 8, 513-519

[45] Zhishu X., Yushan W., Harris M., Zhibin Z., Spatial and temporal variation of seed predation and removal of sympatric large-seeded species in relation to innate seed traits in a subtropical forest, Southwest China, Forest Ecol. Manag., 2006, 222, 46-54

[46] Moles A.T., Warton D.I., Westoby M., Do smallseeded species have higher survival through seed predation than large-seeded species? Ecology, 2003, 84, 3148-3161

[47] Harrison S.K., Regnier E.E., Schmoll J.T., Postdispersal predation of giant ragweed (Ambrosia trifida) seed in no-tillage corn, Weed Sci., 2003, 51, 955-964

[48] Mueller T.C., Massey J.H., Hayes R.M., Main C.L., Stewart C.N., Shikimate accumulates in both glyphosate sensitive and glyphosate-resistant horseweed (Conyza canadensis L. Cronq.), J. Agric. Food Chem., 2003, 51, 680-684

[49] Pline-Srnic W., Technical performance of some commercial glyphosate-resistant crops, Pest. Manag. Sci., 2005, 61, 225-234

[50] Stewart C.N., Another type of superweed? In: Stewart C.N. (ed) Genetically Modified Planet. Environmental Aspects of Genetically Engineered Plants, Oxford University Press, UK, 2004

[51] Sandermann H., Plant biotechnology: ecological case studies on herbicide resistance, Trends Plant. Sci., 2006, 11, 324-328 